\title{
Musculoskeletal wounds characteristic of the Second Lebanon War
}

\author{
Haim Cohen ${ }^{1}$, Viviane Slon ${ }^{1}$, Hila May ${ }^{1}$, Israel Hershkovitz ${ }^{1 *}$, Eli Peled ${ }^{2}$, Doron Norman ${ }^{2}$ \\ ${ }^{1}$ Department of Anatomy and Anthropology, Sackler Faculty of Medicine, Tel Aviv University, Tel Aviv, Israel; \\ *Corresponding Author: anatom2@post.tau.ac.il \\ ${ }^{2}$ Department of Orthopedics and Traumatology “B”, Rambam Medical Center, Haifa, Israel
}

Received 16 January 2013; revised 21 February 2013; accepted 5 March 2013

Copyright (C) 2013 Haim Cohen et al. This is an open access article distributed under the Creative Commons Attribution License, which permits unrestricted use, distribution, and reproduction in any medium, provided the original work is properly cited.

\begin{abstract}
The Second Lebanon War between Hezbollah and Israel broke out on July 12, 2006, and lasted until August 14, 2006. Out of the wounded Israeli soldiers, 128 were treated at the orthopedic departments of the Rambam Medical Center, Haifa, Israel. A retrospective study was carried out on these 128 combatants. The objective of the study was to characterize musculoskeletal combat wounds with regard to age, type, location, mechanism, side and intensity. The average age of an injured soldier was 25.7 years. Most injuries (63.9\%) were caused by shrapnel. The prevalence of injury to the lower limb was much higher compared with upper limb $(43.4 \%$ vs. 28.3\%). There was no side preference. A considerable number of soldiers had more than one injury $(60 \%)$. The majority of wounds that occurred in the Second Lebanon War were orthopedic-related, particularly involving the upper and lower extremities. Fragmenting weapons were responsible for most injuries.
\end{abstract}

Keywords: Second Lebanon War; Musculoskeletal Injuries; IDF; Casualties; Combat

\section{INTRODUCTION}

The "Second Lebanon War" between Hezbollah and the Israeli Defense Forces (IDF) broke out on July 12, 2006 and ended on August 14, 2006. It resulted in 117 Israeli soldiers killed and 725 injured [1].

In the first two weeks of combat, the IDF launched mainly air strikes on Hezbollah strongholds, and consequently the number of casualties on the Israeli side was relatively low. In the following weeks of combat, the number of injured soldiers increased considerably due to extensive involvement of ground troops in the battlefield $[1,2]$.

Most injured soldiers (94\%) died within one hour of their injury. Out of all injured soldiers, 217 were evacuated to the relevant departments of the Rambam Medical Center (Level 1 Trauma Center) [1].

To better cope with future war wounds, in terms of medical care and proper military protective equipment, it is necessary to define the injuries, which occur during battle. The objective of the present study was therefore to characterize musculoskeletal combat wounds, regarding parameters such as type, location, and mechanism.

\section{MATERIALS AND METHODS}

The present research was conducted as a retrospective study of wounded soldiers, who were evacuated to the orthopedic departments at the Rambam Medical Center, during the Second Lebanon War. A battle injury was defined as any casualty incurred as the direct result of hostile action sustained in combat or sustained going to or from a combat mission [3].

Data on injuries were collected from medical files and were analyzed according to injury mechanism, location, intensity and age. Bone fractures, when present, were further analyzed, according to the above-mentioned independent variables. The particular body regions were demarcated according to Owens et al. (2008) [3]. It is worth noting that the upper extremity included the clavicle and scapula, whereas the lower extremity did not include the pelvis, but started at the proximal femur. Statistical analysis was performed using SPSS (version 16.0). The Chi-square test was used to determine the association between parameters. Significance was set at $p<0.05$.

This study No. 0020-12-RMB was reviewed and approved by the Helsinki committee of the Rambam Health Care Campus-Haifa, on January 15, 2012. 


\section{RESULTS}

A total of 128 wounded soldiers were evacuated from the battlefield to the orthopedic departments at Rambam Medical Center. Soldiers were all males, ranging in age from 19 to 46 (mean age $25.7 \mathrm{yr}$ ). Almost 60\% of all wounded soldiers were younger than 24 years of age. It is noteworthy that $18.7 \%$ of the wounded soldiers were over 31 years of age.

\subsection{Mechanism of Injury}

Most of the soldiers (60.1\%) were injured by shrapnel, $14 \%$ by contusion, $11.7 \%$ by unknown mechanism, $6.2 \%$ by bullet, $3.1 \%$ by explosive device, $3.1 \%$ by both explosive device and shrapnel, $0.7 \%(n=1)$ by missile and $0.7 \%$ by both contusion and shrapnel (Figure 1).

\subsection{Location of Injury on the Body}

Most injuries were to the extremities: $43.4 \%$ were to the lower limbs and $28.3 \%$ to the upper limbs. The rest were distributed as follows: $9.5 \%$ to the head, $5.5 \%$ to the shoulder girdle, $3 \%$ to the pelvic area, $2.1 \%$ to the neck and back, $1.2 \%$ to the thorax, and $0.6 \%$ to the abdomen (Figure 2). Injuries were distributed equally between the right and left sides: $37.9 \%$ were located on the right side and $33.8 \%$ on the left side of the body, with the rest (28.3\%) to the mid-body region (Figure 2). In the lower limbs, $38.8 \%$ of the injuries were to the leg, $45.7 \%$ to the thigh, and $15.5 \%$ to the foot. In $21.5 \%$ of the lower limb cases, the injuries were bilateral, in

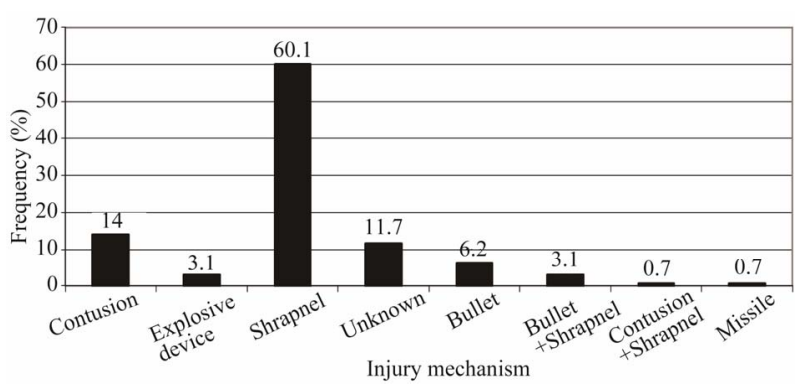

Figure 1. Prevalence of war injuries by mechanism.

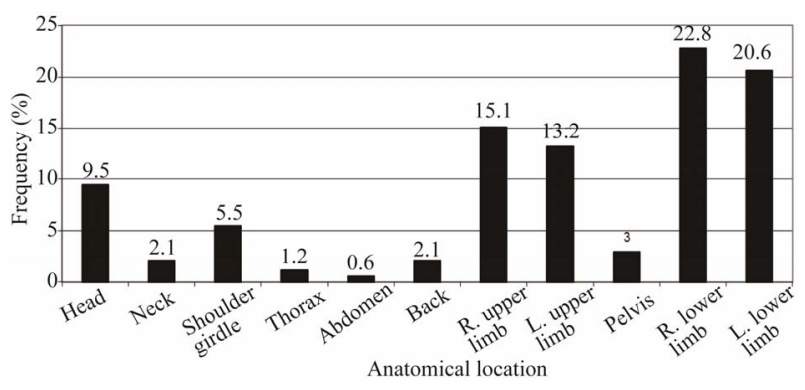

Figure 2. Prevalence of war injuries by anatomical location and side.
$42.2 \%$ they were to the right side and in $36.2 \%$ to the left. In the upper extremity, $34.5 \%$ were to the arm, $30.9 \%$ to the forearm, and $34.5 \%$ to the hand. $9.5 \%$ of the injuries were bilateral, $48.8 \%$ were to the right side and $41.6 \%$ to the left.

\subsection{War Injuries Caused by Shrapnel}

Most of the injuries caused by shrapnel were to the extremities: $39.1 \%$ were in the lower limbs and $30.7 \%$ in the upper limbs. The rest were distributed as follows: $12.3 \%$ to the head, $6.7 \%$ to the shoulder girdle, $4.4 \%$ to the pelvis, $2.8 \%$ to the back, $2.2 \%$ to the neck, $1.1 \%$ to the chest, and $0.5 \%$ to the abdomen (Figure 3). There were three times as many bilateral injuries caused by shrapnel to the lower limbs as to the upper limbs: $24.3 \%$ vs. $7.2 \%$. The detailed distribution of shrapnel injuries to the limbs is presented in Table $\mathbf{1}$.

\subsection{Bone Fracture Mechanisms}

Of the 129 wounded soldiers studied, 26.3\% experienced bone fracture. Most fractures (41.1\%) were caused by shrapnel, $23.5 \%$ by an unknown mechanism, $11.7 \%$ by contusion, $8.8 \%$ by explosive device, $5.8 \%$ by bullet, $5.8 \%$ by both bullet and shrapnel, and $2.9 \%$ by both contusion and shrapnel (Figure 4).

\subsection{Locations of Fracture}

Most fractures (45.3\%) were located in the lower limbs, $33.4 \%$ in the upper limbs, $9.5 \%$ in the head and

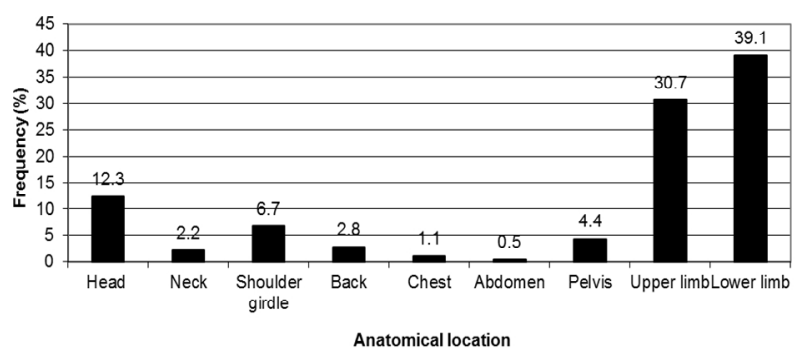

Figure 3. Prevalence of war injuries caused by shrapnel, by anatomical location.

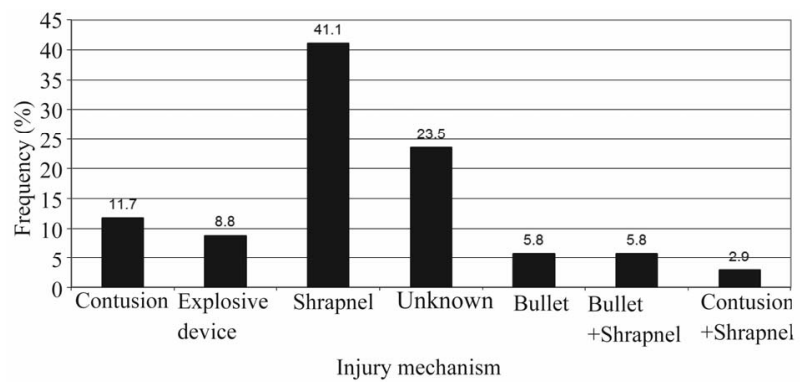

Figure 4. Prevalence of soldiers with bone fracture, by mechanism. 
Table 1. War injuries caused by shrapnel at specific anatomical locations in the upper and lower limbs, by side.

\begin{tabular}{cccccccccc}
\hline & \multicolumn{4}{c}{ Upper Limb } & \multicolumn{3}{c}{ Lower Limb } & Total \\
\cline { 2 - 8 } & Head & Forearm & Arm & Total & Foot & Leg & Thigh & Total & 26 \\
Right & 12 & 7 & 9 & 28 & 2 & 9 & 15 & 54 \\
Left & 6 & 6 & 11 & 23 & 2 & 15 & 10 & 27 & 50 \\
Bilateral & 2 & 1 & 1 & 4 & 2 & 4 & 11 & 17 & 21 \\
Total & 20 & 14 & 21 & 55 & 6 & 28 & 36 & 70 & 125 \\
\hline
\end{tabular}

shoulder girdle, and 2.4\% in the pelvis (Figure 5). While in the upper limbs fractures to the bones occurred equally on the right and left sides, in the lower limbs more fractures occurred on the right side: $54.5 \%$ vs. $31.8 \%$. In the lower limbs, most of the fractures were of the leg (50\%), and in the upper limb, most were of the hands (55.6\%). Almost 30\% of soldiers suffering from fractures had more than one fracture.

\subsection{Intensity of War Injuries}

Most of the wounded soldiers (39.8\%) experienced one injury, $15.6 \%$ two injuries, $16.4 \%$ three injuries, $9.4 \%$ four injuries and $8.6 \%$ five injuries. Overall, there were 365 injuries in various parts of the body of the 128 soldiers, implying 2.85 injuries for every wounded soldier.

\section{DISCUSSION}

Several papers have been published on injuries among Israeli soldiers during the Second Lebanon War $[1,2,4]$. This paper is the first, however, to directly relate to musculoskeletal injuries.

The average age of wounded combatants in the Second Lebanon War (25.7 years) was very similar to that in Operation Iraqi Freedom and Operation Enduring Freedom (26.0 years) [3]. The length of the mandatory military service in the IDF for men is three years, usually served between the ages of 18 and 21 . The high mean age of injured soldiers thus indirectly points to a relatively high rate of injuries among IDF officers and/or reserve forces.

The majority of traumas that occurred in the Second Lebanon War were orthopedic-related, particularly involving the upper and lower extremities (44\%) [1]. However, this rate is much lower than in previous armed conflicts. For example, injuries in the extremities represented 54\% of the wounds in Operation Iraqi Freedom and Operation Enduring Freedom [3], 58\% in World War II (WWII) [5], 60.2\% in Korea [6], and 61.1\% in Vietnam [7]. Interestingly, the rate of injury to the thorax (7\%) and abdomen/pelvis (7\%) [1] falls within the ranges of previous wars: thorax $(5.9 \%-13.9 \%)$ and ab-

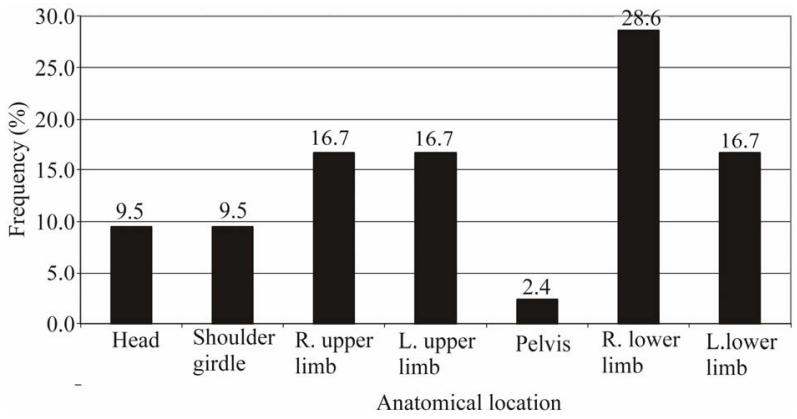

Figure 5. Relative frequencies of bone fractures, by anatomical location.

domen $(8.0 \%$ - 9.4\%) [3].

The next most prevalent anatomical area for injury during the Second Lebanon War was the head and neck (27\%). A similar prevalence (29.4\%) was noted in Operation Cast Lead [8]. Not surprisingly, such a high rate of injury to the head and neck was found only in the most recent wars, such as 30\% during the Iraqi operations [3]. In previous wars in the region, such as the First Lebanon War (1982) and the Yom Kippur War (1973), the rates were $13.5 \%$ and $16.3 \%$, respectively [1]. In WWII, Korea and Vietnam, head and neck injury ranged from $16.0 \%$ to $21.4 \%$ [3].

The decrease in injuries to the extremities may reflect a certain type of warfare, in which infantrymen are carried in, and conduct much of their fighting from, armored vehicles, so that their lower limbs are relatively protected. It may also reflect the fact that soldiers wear body armors, which protect their upper limbs, whereas the head and neck remain more vulnerable to injury.

In the Second Lebanon War, the most common mechanism of musculoskeletal injury was shrapnel (63.9\%), whereas the injury rate due to bullets $(9.3 \%)$ and improvised explosive devices (3.1\%) were low. In the Iraqi operations, explosions were responsible for $81 \%$ of the extremity injuries, gunshot wounds for $17 \%$, and improvised explosive devices for $2 \%$. Gunshot wounds were much more common in WWII (27\%) [5], Korea (31\%) [6] and Vietnam (35\%) [7]. The decline in gunshot wounds among the Israeli soldiers may be due to the tactic practiced by the Hezbollah, namely avoidance of 
short-range battles and reliance on long-range weapons, such as missiles, rockets, and mortars. Blast injuries are in general "dirtier" than gunshot wounds, and carry a higher potential for infection. Although musculoskeletal injuries are associated with a very low mortality rate (when isolated), they may in fact be responsible for significant morbidity.

Finally, in Operation Cast Lead, a large-scale campaign of the IDF against Hamas militants in the Gaza strip (January 2009, 23 war-days), 10 IDF soldiers were killed and 339 wounded. The average number of injuries per soldier was 1.8 (calculated from all injured soldiers) [8], compared to 2.85 injuries per soldier among those who were treated in the orthopedic departments during and following the Second Lebanon War. This discrepancy may be due to differences in the war tactics of both sides and the types of weapon used by the two rivals.

In conclusion, the majority of wounds that occurred in the Second Lebanon War were orthopedic-related, particularly involving the upper and lower extremities. Their rate, however, was lower than in previous wars, possibly due to the increasing involvement of armored vehicles in battles.

Fragmenting weapons were responsible for most injuries. Bullets are no longer a major cause of penetrating injury to the limbs, as they have been replaced in recent wars by fragmenting weapons (Shrapnel) such as bombs, shells, grenades, and landmines. This explains the increased rate of injury per soldier when compared to past conflicts.

This information regarding the characteristics of musculoskeletal war wounds is valuable, as it may allow medical staff to anticipate these types of injuries and take the necessary measures to better treat wounded soldiers in the future. Furthermore, reliable quantitative data on these injuries may be used to better suit military protective equipment to the propensity of injuries in different anatomical locations.

\section{Limitations of Study}

Comparison with other studies can be biased due to variations in definitions. Different inclusion criteria (all wounds vs. only primary or dominant wounds) may also affect the comparisons. Furthermore, the reporting of wounds may vary from file to file.

\section{ACKNOWLEDGEMENTS}

The authors thank the Dan David Foundation and the Tassia \& Dr. Joseph Meychan Chair for the History and Philosophy of Medicine for funding this research. The authors would also like to thank Dr. Laub for English editing.

\section{REFERENCES}

[1] Gal, O., Weiss, A. and Dudckiewicz, M. (2007) Injury characteristics among IDF soldiers during the Second Lebanon War. Journal of Israeli Military Medicine, 4, 3-6.

[2] Schwartz, D., Resheff, A., Geftler, A., Weiss, A., Birenbaum, E. and Lavon, O. (2009) Aero-medical evacuation from the Second Israel-Lebanon War: A descriptive study. Military Medicine, 174, 551-556.

[3] Owens, B.D., Kragh, J.F., Wenke, J.C., Macaitis, J., Wade, C.E. and Holcomb, J.B. (2008) Combat wounds in operation Iraqi freedom and operation enduring freedom. The Journal of Trauma, 64, 295-299. doi:10.1097/TA.0b013e318163b875

[4] Levin, L., Zadik, Y., Peleg, K., Bigman, G., Givon, A. and Lin, S. (2008) Incidence and severity of maxillofacial injuries during the Second Lebanon War among Israeli soldiers and civilians. Journal of Oral and Maxillofacial Surgery, 66, 1630-1633. doi:10.1016/j.joms.2007.11.028

[5] Beebe, G.W. and DeBakey, M.E. (1952) Battle casualties: Incidence, mortality, and logistic considerations. Charles C. Thomas, Springfield.

[6] Reister, F.A. (1973) Battle casualties and medical statistics: US Army experience in the Korean War. University of Michigan Library, Michigan.

[7] Hardaway, R.M. (1978) Vietnam wound analysis. The Journal of Trauma, 18, 635-643. doi:10.1097/00005373-197809000-00004

[8] Ran, Y., Hadad, E., Daher, S., Kasirar, M., Itzhak, A., Yagurov, I., Cohen, Y., Dudckiewicz, M., Bar-Tal, C., Esh, N. and Hirshorn, G. (2009) Injury characteristics among IDF soldiers during operation Cast Lead. Journal of Israeli Military Medicine, 6, 157-161. 